\title{
Iran towards universal health coverage: The role of human resources for health
}

\author{
Elham Ehsani-Chimeh*1, Haniye Sadat Sajadi ${ }^{1}$, Reza Majdzadeh ${ }^{2}$
}

Received: 29 Aug 2018

Published: 16 Oct 2018

\begin{abstract}
Given the key role of adequate, skilled, well-trained, and motivated human resources for health (HRH) in achieving universal health coverage (UHC), this manuscript aimed to investigate the current situation of Iran HRH after the implementation of the recent Health Transformation Plan (HTP) in accordance with UHC analytical framework using 4 domains of availability, accessibility, acceptability, and quality. Conflicts of interest and multiple interventions from different sectors have controversial and sometimes negative effects on the health workforce. Thus, to achieve the objectives of UHC from the perspective of human resources, Iran needs unified governance and comprehensive planning. Also, the effects of health system interventions on health workforce should be assessed before implementation.
\end{abstract}

Keywords: Universal health coverage, Human resources for health, Health transition plan, Health workforce

\author{
Conflicts of Interest: None declared \\ Funding: Declared none \\ *This work has been published under CC BY-NC-SA 1.0 license. \\ Copyright $\odot$ Iran University of Medical Sciences
}

Cite this article as: Ehsani-Chimeh E, Sajadi HS, Majdzadeh R. Iran towards universal health coverage: The role of human resources for health. Med J Islam Repub Iran. 2018 (16 Oct);32:100. https://doi.org/10.14196/mjiri.32.100

\section{Introduction}

In 2012, the United Nations General Assembly bolstered the political support of the universal health coverage (UHC) and emphasized that achieving UHC involves distributing resources, particularly human resources for health (HRH), to match the health needs of populations (1-6). Given the key role of adequate, skilled, well-trained, and motivated HRH in achieving UHC (710), this manuscript aimed to investigate the current situation of Iran HRH. To this end, first, all national policies affecting HRH in Iran were reviewed. Then, the status of HRH after the implementation of the recent Health Transformation Plan (HTP) (11) was analyzed in accordance with UHC perspective. Adopted analytical

\footnotetext{
*Corresponding author: Dr Elham Ehsani-Chimeh, ehsanielham@yahoo.com

1. National Institute for Health Research, Tehran University of Medical Sciences, Tehran, Iran

${ }^{2}$. Knowledge Utilization Research Center, Community-Based Participatory-Research Center, and School of Public Health, Tehran University of Medical Sciences, Tehran, Iran
}

framework, which was designed based on "UHC cube"(12), was applied for the HRH to characterize the dimensions of effective coverage: availability, accessibility, acceptability, and quality (AAAQ) (Fig. 1) (13). The framework shifts the focus from AAAQ dimensions of the health workforce into the quality of care, which shows the "effective coverage gap".

\section{Reforms and polices affecting HRH in Iran}

In 2015, there were $667111 \mathrm{HRH}$ in Iran who were affected by multiple organizations in policy and service delivery domains (14). After the Islamic Revolution, several health system reforms were undertaken to achieve

$\uparrow$ What is "already known" in this topic:

Human resources for health (HRH) and having adequate, skilled, well-trained, and motivated HRH are considered as key elements in achieving health outcomes and attainment of UHC. Investigating HRH from availability, accessibility, acceptability, and quality aspects provides good evidence about effective coverage gap and UHC attainment.

$\rightarrow$ What this article adds:

Conflicts of interest and multiple interventions of different sectors in HRH have controversial and sometimes negative effects on the health workforce in Iran, thus, to achieve UHC objectives, unified governance and comprehensive planning are needed. Assessing the effects of health system interventions on health workforce before implementation can be useful. 


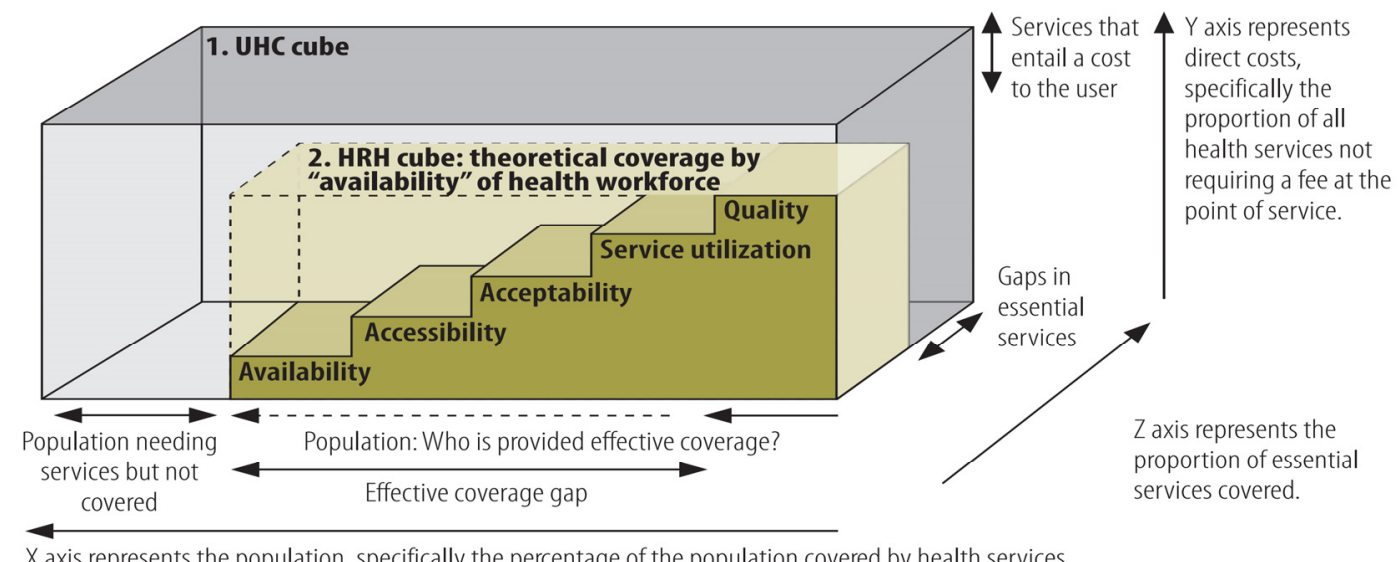

Fig. 1. Dimensions of universal health coverage (UHC) pertaining to human resources for health (HRH): Effective coverage

UHC goals, some of which directly influenced the health workforce.

One of the most important reforms affecting HRH was the integration of medical education in the Ministry of Health and establishment of a new ministry called Ministry of Health and Medical Education (MOHME), with the aim of overcoming the shortage of health professionals. At that time, there was only 1 physician for every 18000 people in some parts of Iran. The integration of medical education led to an increase in the number of medical education centers, medical and paramedical sciences fields, and faculty members, which all led to a significant increase in HRH (15). Medical Mandatory Service Plan was another policy conducted in 1988 , according to which each medical and paramedical student who graduate in or out of Iran had to dedicate 24 months to compulsory services in the areas required by MOHME. HRH in the public sector of Iran followed the governmental employment laws of the country until 1988. After the implementation of the new system of hospital administration, the issue of paying fee-for-service to staff, especially to physicians, was highlighted, leading to a paramount impact on the use of health services and out-ofpocket payment in the following years. Subsequently, performance-based payment was proposed in the Comprehensive Plan for Amending the Economical and Management Structure of Hospitals reform. This plan was only implemented for several years in the selected hospitals which had board of trustees. During these years, the recruitment of government-funded HRH was carried out in line with the needs expressed by MOHME and in accordance with the annual governmental resources limitation. In the private sector, the same as other sectors, the regulations were determined by the employers; however, the minimum wage was only set by the Ministry of Labor and Social Affair. Government's policy towards privatization was introduced in 1999, according to which some of personnel of supporting services and even some of the health workforce were transferred to the private sector. However, due to large shortcomings of this plan, these workforces eventually returned to governmental sector in 2003.
Policies, such as Family Physician Program (the law of improving the productivity of clinical staff and reducing working time of clinical staff), Health Messengers (compulsory military service for graduates of the medical group), etc., were among minor interventions affecting the health workforce. It seems that the most important corrective action by MOHME about its affiliated workforce was the approval of administrative and employment regulation for the faculty and non-faculty staff of medical universities. This measure led to the independence of medical universities in the administrative field and improved the payment of workforce in this sector, especially in health staff. Despite these interventions, dissatisfaction of $\mathrm{HRH}$, especially physicians, unrealistic tariffs, inequality in the payments of various occupational groups, particularly physicians, different employment relationships, imbalance between supply and demand of HRH, lack of workforce, and disproportionate distribution $(16,17)$ led to inclusion of interventions related to HRH in HTP (2013), which has been implemented since 2014. These interventions are presented in Table 1.

\section{Availability of HRH after implementation of HTP}

In Iran, there was $1 \mathrm{HRH}$ for every 118 people in 2015, $79 \%$ of whom were employed in the public sector. There are 1.14 physicians, 0.33 dental practitioners, and 1.87 nurses and midwives per 1000 population (14). The implementation of HTP could increase the number of public workforce; the number of general practitioners working in health centers increased from 1498 to 13052 in 2016 (18); in addition, the graduation rate reached $3.7 \%$. On the other hand, before the implementation of HTP, the workforce sector (recruitment and maintenance) worked separately from the medical education sector (training), which led to imbalance between the supply and demand of HRH. Following the development of the curative affairs road map (2017) and estimation of the required health workforce, the country's medical education transformation plan has been implemented since 2018; henceforth, the health workforce production is 
Table 1. Interventions related to HRH in HTP

- Rationalizing tariffs and compilation of a book on the relative value of health services in inpatient and outpatient care

- Implementing a program supporting the inhabitancy of physicians in deprived areas

- Implementing a program supporting the presence of specialists in the MOHME hospitals

- Improving the quality of health care services in MOHME hospitals

- Recruiting full-time faculty staff

- Performance-based payment to personnel in MOHMEhospitals (called MOHME hospitals (Qasedak plan)

- Implementing primary care and public health dimensions of the HTP and recruiting new occupational groups for health centers

- Recruiting HRH, especially nurses, to improve workforce indexes and for new centers

- Revising the administrative and employment regulation for medical faculty and non-faculty staff

- Prioritizing the recruitment of domestic workforces, revising recruitment contracts, and increasing commitments in deprived areas

- Projecting HRH requirements and developing a treatment plan for estimating available workforces and required workforces in the next 10 years

- Developing a transformation plan for medical sciences in the country

- Training to enhance skills and empowering primary care managers and health service providers

- Establishing a supreme institute for training health system managers and holding hospital management courses

- Establishing a specialized company for outsourcing HRH

based on demand while prioritizing domestic workforces (19). The establishment of a specialized HRH company led to employment of qualified health workforces in hospitals and government centers over the past 3 years, while its financial source has been provided by special income of medical universities.

\section{Challenges and solutions}

The recruitment of $\mathrm{HRH}$ in the public sector has increased during the implementation of HTP, but its maintenance requires sustained financial resources.

The HTP has not revised medical disciplines and their educational contents; however, in some disciplines, curriculum needs a general overview based on the needs of the community. Thus, new disciplines should be introduced while others should be eliminated. The labor market and induced demand in some services should be considered in developing new disciplines and specializing medical disciplines.

Modification of tariffs and the definition of the relative value of health services are also part of the measures taken to maintain the available specialized workforces in the country, whose impact should be evaluated. In addition, one of the main problems of Iran's health system is the total health expenditure, which is quite high (11). Therefore, increasing tariffs might further increase the expenditure and if it does not increase the efficiency of the system, then it can be considered as a very negative factor.

Adopting professional code of practice is another way to facilitate the recruitment of qualified workforces from other countries and omission of workforces in surplus disciplines.

\section{Accessibility of HRH after implementation of HTP}

The full-time equivalent (FTE) of most of HRH groups is higher than 1; for instance, it is 1.4 for nursing and midwifes. The distribution of HRH is not balanced in different provinces and cities of the country; for example, the distribution of physicians per 1000 population is 2.20 in Tehran (the highest) and 0.53 in Sistan and Baluchestan (the lowest) (14). Plans, such as inhabitancy of physicians in deprived areas, specialists' inhabitancy in MOHME's hospitals, full-time plans, recruitment of native workforces, the 10-year work commitment for governmental employment, performance-based payments, reduction of compulsory services in deprived and less developed areas, etc., are among interventions developed during HTP to maintain health workforces in the country and in less developed regions. Accordingly, the number of hospitals with resident specialists increased from 91 to 408 hospitals by 2017, and the number of resident specialists increased to 4330. During the inhabitancy of physicians in Deprived Areas Plan, the number of specialized physicians in deprived areas increased from 941 to 5992 (18). Thus, it seems that the implementation of these plans can increase the accessibility to health workforces in different regions.

\section{Challenges and solutions}

It appears that HTP interventions have been effective in increasing access to health services; however, maintaining these interventions requires sustained financial resources. If sustainable resources are not provided, high health workforce dissatisfaction can decrease access to health, especially in underdeveloped and deprived areas, even less than that before the implementation of HTP. Currently, delay in the payments of workforces has led to high dissatisfaction, which can increase informal payments in the long run while adversely affecting HRH accessibility. The significance of this issue can be touched by the reduction of specialized physicians' willingness to reside in deprived areas after fulfilling their compulsory services (reduction from $59.5 \%$ to $40 \%$ in 2016) (18). In addition, one of the goals of these plans was to reduce physicians' dual practice in the public and private sectors; however, no solid evidence exists in this regard. Nevertheless, conflict of interest prevented prohibition of physicians' dual practice. One of the challenges against performance-based payment intervention is inequality in the payments of different occupational groups and various sectors, which can lead to high dissatisfaction and transfer of health workforces from primary health care to hospital departments, leading to decrease of accessibility to HRH. Additionally, the real effect of this payment system on informal payments requires further investigation. The effectiveness and efficiency of incorporating some of disciplines to health centers is one of the issues that have not yet been addressed. 
Acceptability of HRH after implementation of HTP

Recruitment of domestic workforces can enhance accessibility and acceptability to HRH because of familiarity with culture, economic and social conditions, and even familiarity with the climate of the region. Fortunately, this has been included in both medical education policies and recruitment interventions. In addition, because of the implementation of the Islam Adaptation Plan in Iran (separation of males and females in hospital wards and also allocation of same gender staff for them) and the culture of people in different parts of the country, gender is an important factor in recruitment of health workforces, which has also been taken into consideration in recruitment interventions.

\section{Challenges and solutions}

The important issue, along with aforementioned factors in acceptability-related interventions, is that ethnic and religious status of Iran affects the acceptability of HRH, which has not yet been taken into consideration yet.

\section{Quality of HRH after implementation of HTP}

To improve the quality of health workforce, training courses were held for the HRH in the form of continuous medical education and in-service training. Also, special courses were conducted for the health system managers. To improve quality of visits in MOHME's hospitals program, the time of physician visits was standardized and special attention was paid to clinical examinations. In the payment intervention, including the health and hospital sectors, working experience had an effect on the payment. The classification of HRH roles was reviewed in 2013, and the career development path was identified for some groups. Absorption indicators of the HRH were reviewed and specialized courses and interviews were included in recruitment programs and, thus, the quantitative indicators for absorption of HRH increased (workforce number per bed or population). However, the results of studies showed that after implementation of HTP, satisfaction of physicians who worked in deprived areas decreased from $82 \%$ in autumn of 2014 to $42 \%$ in autumn of 2015 .

\section{Challenges and solutions}

The training of HRH can be used as a tool to increase the quality of services and their better acceptance by the society. We reviewed the few available studies, interviewed with the policymakers, and found that conducting educational courses (in-service training) has been neglected in Iran. Regarding the classification of occupations in HRH, it seems that the review just focused on the public sector and only explained the duties related to each occupation. However, considering the lack of workforce in certain occupations, it is better to study other options, such as changing the scope of practice and taskshifting. Another problem is lack of an accreditation system in HRH for all the related businesses; there is only an accreditation system for physicians, which is imperfect and inadequate. The other issue affecting the quality is the mismatch of the criteria and standards for absorption and promotion of the faculty members with the needs of the health system. The lack of motivation among the workforce is another major problem in the quality of HRH that the HTP was not able to improve. The lack of a motivation system, job insecurity, inequalities created by different payments of various occupational groups, especially physicians, and different employment relationships, especially after the HTP, are among the other major problems that affect the quality of work done by the HRH. Another major challenge is that the amount of job performed by HRH and its measurement criteria are vague and that the HTP has only considered the number of services performed by the workforces; and this in turn led to an increase in the number of services, induced demands, and health costs.

\section{Conclusion}

The lack and, in some cases, inflation of the HRH, weakness in retention and motivation of the workforce, lack of a comprehensive system for HRH management, inadequate and sometimes, contradictory laws, lack of unity in the implementation of laws, and existence of various interpretations from laws, shifting workforces from different sectors, unequal geographical distribution of HRH, as well as existence of evidences regarding the inefficiency of human resources indicate weakness in the management of HRH. The health human resource system in the health sector is a vast system consisting of components that require integrated management. Conflicts of interest and multiple interventions from different sectors have controversial and sometimes negative effects on the health workforce. To achieve the objectives of UHC from the perspective of human resources, Iran needs unified governance and comprehensive planning. Also, the effects of health system interventions on health workforce should be assessed before implementation.

\section{Conflict of Interests}

The authors declare that they have no competing interests.

\section{References}

1. Anand S, Bärnighausen T. Health workers and vaccination coverage in developing countries: an econometric analysis. Lancet. 2007; 369(9569): 1277-85.

2. Anand S, Bärnighausen T. Human resources and health outcomes: cross-country econometric study. Lancet. 2004;364(9445):1603-9.

3. Pong RW, Pitblado JR. Geographic distribution of physicians in Canada: beyond how many and where: Canadian Institute for Health Information= Institut canadien d'information sur la santé; 2005.

4. Nasiripour AA, Maleki MR, Tabibi SJ, Ehsani-Chimeh E. Factors Influence on Geographic Distribution of Physicians in Selected Countries; A Review Article. J Kermanshah Uni Med Sci. 2013; 17(9):600-10.

5. World Health Organization. The world health report 2006: working together for health: World Health Organization; 2006.

6. Hongoro C, McPake B. How to bridge the gap in human resources for health. Lancet. 2004;364(9443):1451-6.

7. Feldbaum H, Lee K, Michaud J. Global health and foreign policy. Epidemiol Rev. 2010;32(1):82-92.

8. World Health Organization. Sustainable health financing structures and universal coverage. Resolution WHA64. 2011;9.

9. World Health Organization. World Health Report, 2010: health 
systems financing the path to universal coverage. World Health Report, 2010: Health systems financing the path to universal coverage. 2010.

10. Sheikh M, Boerma T, Cometto G, Duvivier R. Human resources for universal health coverage: a call for papers. Bull World Health Organiz. 2013;91(2):84-a.

11. Sajadi HS, Ehsani-Chimeh E, Majdzadeh R. . Universal Health Coverage in Iran: where we stand and how we can move forward. Med J Islam Repub Iran. (In Press).

12. Ooms G, Brolan C, Eggermont N, Eide A, Flores W, Forman L, et al. Universal health coverage anchored in the right to health. SciELO Public Health; 2013.

13. Campbell J, Buchan J, Cometto G, David B, Dussault G, Fogstad H, et al. Human resources for health and universal health coverage: fostering equity and effective coverage. Bull World Health Organiz. 2013;91:853-63.

14. Gharib_Naseri Z, Ehsani-Chimeh E, Goudarzi Z. Physical and Human Resource of Health System in Iran. In: Harirchi I, Majdzadeh SR, Ahmadnezhad E, Abdi Z, editors. Observatory on Health System, Islamic Republic of Iran. Tehran, Iran: National Institute of Health Research; 2017.

15. Haghdoost AA, Kamyabi A, Asgarabad AA, SadeghiradB, Shafieian H, SH G. Geoghraphic Distribution of Medical groups and Provincal imbalences in Iran. J Med Council. 2010;28(4):411-9.

16. Salehi-Zalani GH, Bayat M. Iran Health Sector Human Resuorces Requirment Projection Vision 2025. 1st ed. Tehran, Iran: Ministry of Health and Medical Education; 2015.

17. Ehsani-Chimeh E, Behbahani AA. Factors Affecting the Service Delivery Locations of Newly Graduated Iranian General Practitioners. Iran Red Cres Med J. 2017;19(2).

18. National institute for Health Research. National Institute for Health Research Report on Health Transformation Plan. Tehran: National Institute for Health Research (NIHR). 2016.

19. Pourabbasi A, Haghdoost AA, Akbari H, Kheiry Z, Dehnavieh R, Noorihekmat S, et al. Packages for reform and innovation in medical education in Islamic Republic of Iran; a conceptual framework. Teb Tazkieh. 2017;26(1):45-50. 